\title{
THE FUNCTIONS OF A PSYCHOLOGIST IN A HOSPITAL FOR THE INSANE.*
}

By SHEPHERD IVORY FRANZ, Pr. D., M. D., LL. D., Scientific Director Govermment Hospital for the Insane; Professor of Physiology, George Washington University.

The functions or duties of an employee of a mercantile establishment have to a great extent been determined or limited by custom. This statement applies particularly to those who are members of trades unions but it is also applicable to most other workers. The individual who is employed as a porter, or as a bookkeeper, or as a salesman, or as an overseer, is, if he has had any previous experience in such a position, the possessor of knowledge regarding the general duties which he may be called upon to perform, or the tasks which may be required of him. There is, we may say, a social understanding of his general relations to the community with which he becomes connected. Recently, on account of developments in the industrial world older conceptions of the duties of employees have undergone considerable change in certain businesses, and in an up-to-date business each and every employee has the ideals of the establishment set before him. In the department store, for example, the porter not only loads and unloads, and transfers to different parts of the building, cases of goods, but if he has properly absorbed the ideals of the store, he continually seeks to discover means of preventing waste, and at the same time he becomes a potential seller of merchandise. In the factory advancing along modern lines the bookkeeper concerns himself not only with invoices and bills and costs and income, but he becomes a factor in increasing the output of the plant, in bettering the quality of the manufactured articles, and in devising means for enlarging the uses to which the establishment may be put.

Speaking broadly, the above considerations should hold for the functions and duties of a psychologist in a hospital for the insane. There is the distinction, however, that there is no extended period of time and there is no extensive number of those who have been

* Read at a joint meeting of the American Psychological Association and Section $\mathrm{H}$ of the American Association for the Advancement of Science, San Francisco, August 5, 1915. 
employed as psychologists in institutions for the insane, and we cannot appeal to history or to tradition, and not much to custom, to set the limits or breadth or character of the functions of the psychologist in this possible line of endeavor.' We are, therefore, forced to seek elsewhere for the conception of his functions. This is to be found in the hospitals themselves.

A number of years ago the late Dr. Weir Mitchell became unpopular in psychiatric quarters for a time by his characterization of the institutions for the insane as huge caravansaries or boardinghouses. The critical observer at the present time may well wonder whether or not Dr. Mitchell's animadversions had produced any lasting effect. It is apparent that many of our asylums, some of which are masquerading under the name of hospital, have not advanced beyond the stage of belief that the main reasons for their existence are to protect the patient against his own anti- and unsocial acts, to protect the community against the possible misdemeanors of the patient, to see that the patient if he is not bodily ill does not become a total burden upon the state by keeping him occupied with some harmless but value-producing occupation, in some cases to record his history and make a diagnosis when his condition conforms to text-book accounts, and to prescribe suitable doses of cathartics and other simples when such drugs appear to be needed or are asked for by the patient.

\footnotetext{
'The history of the employment of professional psychologists in institutions for the insane forms an interesting chapter in the history of the development of psychology in this country, which cannot be dealt with in detail at this time. Several important events may be mentioned. President G. Stanley Hall while Professor of Psychology in the Johns Hopkins University was superintendent of a public asylum for the insane in Baltimore. Dr. Boris Sidis was associate in psychology and psychopathology in the Pathological Institute of the New York State Hospitals when it was under the direction of the late Dr. Ira Van Gieson, but his employment was ohjected to by the State Commission in Lunacy (judging from the reported communications between Dr. Van Gieson and that body). For a subsequent period of a dozen or more years no such non-medical psychological investigator was employed in that institute. It is also of interest to note that although the psychological aspects of insanity have recently been emphasized (perhaps over-emphasized), the employment of professional psychologists in psychiatric institutes in this country is not only far from general but rather the exception. The demands for a specific "medical psychology," whatever that may be, and perhaps also a reaction against the type of popular psychologizing in some quarters are probably responsible in large part for this state of affairs.
} 
The steward, or financial officer, of one of our larger institutions for the insane, one with over 2000 patients, is reported to have recently said that with the aid of a good physician he could carry on the work of the institution in a proper manner and one which would fulfill its functions." Such a statement indicates a view held not only by some of the laity regarding the functions of hospitals for the insane, but at the same time mirrors the medical ideas of many physicians regarding the places in which the insane are incarcerated. The term incarcerate is used advisedly in this connection, for although it has become customary to designate such places hospitals, in many cases they remain far from hospital ideals and far from the practices of the general hospital to which they are supposed to conform. It is not an exaggeration to say that many of the institutions for the insane in this country remain at the boarding-house stage which was so aptly characterized and condemned by Dr. Mitchell, and signs are present that in not a few cases the institutions are not kept up to good boarding-house standards.

In institutions such as have been described the psychologist as a psychologist could have no function, for he would be neither jailor, nor physician, nor bookkeeper, nor cook. In such an institution he could do only what could be done by any other intelligent, sympathetic, scientific layman, or by a wide-awake physician. He could note the lack of interest in the purely medical problems, he could see the routine methods of dealing with the patients as cases rather than the scientific and progressive method of considering them as individuals, he would have forced upon his notice the exaggeration and almost exclusiveness of the importance of the bookkeeping of the institution, and he might observe with wonder the general lack of those ideals and practices which make for medical advance in the understanding and care and treatment of those who, because of their infirmities and for social purposes, are deprived of their liberty and committed to the care of the institution. At the same time, as an intelligent citizen, he might be able to raise his voice in protest against the travesty of institutional care and treatment, and in that way his efforts might be of value. As a

\footnotetext{
'One is tempted to ask sarcastically why a physician should be added to the staff of such an institution. He would appear to be an unnecessary luxury.
} 
460 FUNCTIONS OF A PSYCHOLOGIST IN INSANE hospital [Jan.

psychologist, supposing he were employed through some misadventure, his functions could not be like those of any other psychologist in the world.

It is only in those institutions in which there exist the highest ideals of the functions of the institutions toward the community at large as well as toward the individual patient that the psychologist may rightly be employed and carry on work. For the understanding of the possible functions of the psychologist one must seek, therefore, for the ideals of the hospital, one must consider what the most advanced institutions are striving to do, and then we shall be able to discover whether or not there are peculiar functions for a psychologist in an institution for the insane.

The public, or semi-public, institution for the insane has officially the function of caring for, protecting, and treating the special diseases of its patients, and of segregating the patients so that they do not disturb the peace and comfort of other citizens. These funcions are not, however, the only functions of a hospital for the insane, for although not often specified in their charters or in the legislative acts of establishment the hospital exists also to perform other duties and to fulfill other obligations to the community. These duties and obligations are those which refer to the advancement of our knowledge regarding mental diseases, their relationships, their origins, their treatment, and their possible prevention. This means that the rightly named hospital for the insane has as its aim not solely the housing, the feeding, and the treatment of its patients according to current widely-accepted views, but also the scientific attitude of inquiry regarding the nature, the course, and the outcome of the different diseases. It is only in institutions in which the spirit of scientific inquiry exists that the psychologist may have functions apart from those of the physician, and the butcher, and the stenographer, and the host of other employees necessary for the conduct of an asylum.

It is only in those institutions in which in addition to a distinct recognition of obligation to care for the living patient there is also an expressed avowal to do all those things which will enable the institution to care for future patients more adequately in every respect and to serve the community, present and future, to the greatest extent, that a psychologist has a place. In such institutions the advancement of our knowledge of mental diseases is coordinate with the function of maintenance of patients. In them 
the effort will be made to understand the patients, to discover all that can be discovered regarding the different diseases, and the effects upon the patients of advocated and supposititious therapeutic measures. The physicians in them will not contentedly wait for the knowledge of advance which is being made in other institutions, but they will be ready and anxious to cooperate and to do their part in the investigation of patients so that progress in the understanding of mental diseases may be made. In institutions of this kind investigation which will help toward the analysis of symptoms or conditions, or which may show relationships of genesis, or of effects, or which may give correlations of other kinds, is the goal. In this work of investigation the psychologist has a place on the same plane as the expert chemist, and the microscopist, and the serologist. The functions of a psychologist in a hospital for the insane may, therefore, be summed up in the one word investigation.

This is not the time or the occasion for suggesting specific problems regarding insanity which may be investigated by a psychologist, nor is it necessary to show in what ways psychological investigations by professional psychologists or by others have helped toward an understanding of the abnormal mental processes of the insane. It is more profitable to consider the general relations of the psychologist.

The psychiatrist as a physician is interested in disease forms, in their origins, in their courses, in their delimitation, and in their therapy. In other words, he is concerned with the combinations which are called diseases. His efforts as a physician are devoted to the diagnosis of the diseases and to the treatment of the patients. These interests of the physician are not the only ones he may have, but they are interests which pertain particularly to him as a medical man. In such matters the psychologist, as a psychologist, has little or no concern, and in so far as he exhibits such interest and occupies himself with them does he leave his psychology to wander into the adjoining field of the psychiatrist. But the same patients whom the psychiatrist examines for symptoms which will permit him to make a differential diagnosis and which will indicate to him directions for treatment are at the same time subjects of the psychologist's interest. The psychologist as a psychologist is, however, concerned not with the diagnosis or the genesis of the diseases but with the origin of particular mental events or pro- 
462 FUNCTIONS OF A PSYCHOLOGIST IN INSANE hosPital [Jan.

cesses. He busies himself with the possible correlations of the mental states but not with them as combinations which point the way to differential diagnoses. The reasons for the incorrect interpretation of certain stimuli and the subsequent " normal" interpretation are points which he seeks to discover. He also desires to analyze those mental conditions which appear to change from day to day to see whether or not they have direct relations, and he wishes to observe and to compare the behavior of different individuals when subjected to the same forms and intensities of stimuli. The psychologist deals with the same material as the psychiatrist but from a different angle, and in so far as the psychiatrist takes the psychological view-point he leaves his medical speciality for an excursion into the adjoining scientific domain.

At the same time the psychiatrist is chiefly concerned with the possibility of the return of the patient to society. He seeks for means of changing the abnormal methods of function, which are called disease, into the more normal channels which will enable the patient to take up his work, his social duties, and his avocations. The psychologist in his investigations is not concerned with treatment and with cures or recoveries. He is interested in the changes from " normal" to "abnormal" and back to "normal" again, and he rightfully seeks to discover reasons for these changes. He may also investigate the gradual loss of certain mental capabilities, from " normal " to " decrease" to "loss," and may seek to discover means of retarding or of stopping or of altering the character of these abnormal variations in such individuals.

The psychologist's functions are principally to gather descriptive facts, to compare the abnormal with the normal, and when possible, to explain the relationships of specific mental conditions. This work entails not infrequently the investigation of the normal by methods which are applicable to the insane, and he must frequently seek confirmation or disproof of previous work by other methods on normal individuals. At the same time new methods must be devised to meet new situations, for the investigation of conditions which are found in the insane but apparently nor in normal people. Frequently new methods must be applied or devised to demonstrate when possible the relations of peculiar states of the abnormal to similar ones in the non-insane. He may also attempt to produce temporary abnormal conditions in normal people for the sake of determining facts which may help toward 
an understanding of the more prolonged mental changes which make up a psychosis, and which are produced by exogenous or endogenous toxins, or by other physical or by mental events.

It is not only with those things which, strictly speaking, are to be called mental that the psychologist must deal. Above all he must be an investigator of mental things, and he must follow these wherever they lead. In his investigations of the insane he must be free to wander into the domain of the physical if the mental conditions he investigates appear to have direct relations with the physical. There has been a too frequent tendency of late years to overlook the physical or to push it to the background, or to erect a high artificial barrier against excursions from one side to the other. To the investigations of a psychologist in a hospital for the insane such barriers are harmful because there are ample demonstrations of the mutual inter-dependence of the physical and the mental. If he is to seek for correlations or for explanations, the physiological and the anatomical and the pathological facts must not be considered to be strangers, but they should be met and welcomed; sometimes they must be sought out when they are not at hand, and they must be given their due weight in the consideration of the mental.

In other words, if his work is to be fruitful in the discovery of new facts and new relationships which help to an understanding of the insane, the psychologist cannot be confined to a narrow strip of land, whether this strip be separated from other adjoining fields by wire fences through which he may look but over which he may not climb, or by high stone walls like those of a prison beyond which he cannot see. It is against a narrow view of the functions of a psychologist that we must exert our efforts, and it is because of the narrowness of some of the recent applied psychology that the science is deprecated by more than a few of our psychiatrists and neurologists.

This leads to a more specific consideration of some of the kinds of psychology. The functional and the analytic have too frequently been considered to be antagonistic, and in recent years it has been the fashion to magnify the importance of the functional and to minimize the value of the analytic. This has been done more especially by psychologizing psychiatrists whose conceptions of functional psychology, as judged by their utterances, consist in the frequent use of loose terms and in the grouping of suppositions 
FUNCTIONS OF a PSychologist In INSANE hospital [Jan.

and so-called facts. To some devotees of the functional psychology the thorough examination of skin and organic sensations in a patient who gives evidence of having somatopsychic delusions may appear futile, since it is assumed that habits of thought, previous mental traumata, and a variety of other mental things are all-sufficient explanations of the delusional state. Critically it appears that by such psychologists the temporal sequence is frequently transformed (as a wish-fulfilment, it may be) into one of cause and effect. The terms psychogenesis, mental conflict and mental mechanism, psychic trend, and a variety of others are used without sufficient analyses of the conditions which they are intended to describe and without a clear definition of these functional terms. This is not to say that functional psychology is valueless. It is only to indicate that in my opinion not all of the so-called functional psychology is of value for the understanding of the insane, and, furthermore, that not all of the so-called functional psychology is psychology. It is probably best that some investigators attempt analyses and that others seek for functional relations, but for the understanding of mental events in the life of the individual both forms of psychology must eventually be used. The kind of psychology is of less importance than that the psychology be scientific.

One other function that a psychologist may have in a hospital for the insane merits brief mention. This is the creation or the advancement of a scientific attitude toward mental diseases in those who are entrusted with the care of patients. Although much has been said regarding scientific medicine, and much effort has been expended to bring about a more scientific attitude in physicians and surgeons, there remains much to be done before the scientific spirit of inquiry and of doubt and of directive effort at advance can be instilled into those who have charge of insane patients. It is, therefore, in his general relations to medical men that the psychologist (but perhaps in this respect not more so that any other investigator) can have a function in a hospital for the insane. By his questions, by his expressions of doubt, by his suggestions of new methods, by his criticisms of loose terms and false connotations, by his enthusiasm, and by his insistence upon the distinction between facts and speculation, the psychologist can, acting through his medical associates, play an important part in the development of psychiatry. 